\title{
Surface Characterization of Chemically Treated Aluminium Nitride Powders
}

\author{
R. Metselaar, R. Reenis, M. Chen, ${ }^{*}$ H. Gorter \& H. T. Hintzen \\ Centre for Technical Ceramics, Eindhoven University of Technology, PO Box 513, Eindhoven, The Netherlands
}

(Received 30 January 1995; revised version received 19 May 1995; accepted 22 May 1995)

\begin{abstract}
The surface characteristics of pure AlN powders are compared with those of so-called water stabilized powders. Both commercially available powders and stearic acid coated powders are used. By means of $X P S$, diffuse reflectance infrared spectroscopy and thermally programmed desorption mass spectrometry, information is obtained about the presence of surface groups. The behaviour of the different powders in aqueous suspension is compared by means of $\mathrm{pH}$ measurements and determination of the isoelectric points.
\end{abstract}

\section{Introduction}

The behaviour of powder suspensions is largely controlled by the surface chemistry of the solid. Also the sintering behaviour is influenced by the presence of physisorbed and chemisorbed surface groups. In nitride powders the surface oxygen content is also of particular importance for the sinterability. In case of AlN the oxygen content also influences the heat conductivity of the dense material. The chemical stability of AlN powders against oxidation and hydration is low and in water hydrolysis takes place. The reaction with water molecules is so fast that slip casting in aqueous suspensions is in fact not possible. For this reason some manufacturers produce AlN powders which have been treated chemically to increase the water resistance. Little is known about the surface chemistry of such AlN powders. Bowen et al. ${ }^{1}$ showed the hydrolysis of uncoated AIN using diffuse reflectance infrared spectroscopy (DRIFT). A surface layer of stoichiometry close to $\mathrm{AlOOH}$ is formed, which gradually transforms into $\mathrm{Al}(\mathrm{OH})_{3}$ according to the reactions:

*On leave of absence from Guanxi University, Nanning, PR China.

$$
\begin{gathered}
\mathrm{AIN}+2 \mathrm{H}_{2} \mathrm{O} \rightarrow \mathrm{AlOOH}_{\text {amorph }}+\mathrm{NH}_{3} \\
\mathrm{NH}_{3}+\mathrm{H}_{2} \mathrm{O} \rightleftharpoons \mathrm{NH}_{4}^{+}+\mathrm{OH}^{-} \\
\mathrm{AlOOH}_{\text {amorph }}+\mathrm{H}_{2} \mathrm{O} \rightarrow \mathrm{Al}(\mathrm{OH})_{3}
\end{gathered}
$$

This reaction is strongly dependent on $\mathrm{pH}$ and temperature. ${ }^{2}$ Egashira et $a l .^{3,4}$ suppressed the surface reactivity using carboxylic acid adsorption. They assume that surface hydroxyl groups play an important role during the adsorption, according to a reaction

$$
=\mathrm{Al}-\mathrm{OH}+\mathrm{HOOC}-\mathrm{R} \rightarrow=\mathrm{Al}-\mathrm{O}-\mathrm{C}-\mathrm{R}+\mathrm{H}_{2} \mathrm{O}
$$

To obtain more insight in the surface chemistry we have used different surface characterization techniques. In this paper we present results of characterization of pure and so-called water-resistant AlN powders.

\section{Experimental}

Table 1 gives a survey of the specifications of the powders used. Powders C and D (A100 and A200 from Advanced Refractories Technologies, ART, Buffalo, NY, USA) and E (Toyalnite WF from Toyo Aluminium K.K., Osaka, Japan) are commercially available water-resistant powders. AIN powder A (grade C from Starck, Berlin, Germany) was tested as-received and compared with the water resistant powders. Powders B were the Starck $C$ powders coated by us according to the procedure described by Egashira et al. ${ }^{3}$ Powder B1 was coated with stearic acid by refluxing in benzene, for powder B2 cyclohexane was used as a solvent. Further details are given in Ref. 5.

The reactivity in water was measured by following the change in $\mathrm{pH}$ for $0.05 \mathrm{wt} \%$ suspensions. To obtain a stable suspension of the powders $\mathrm{C}$ and D $1 \mathrm{wt} \%$ of the deflocculant Triton X100 (a polyoxyethylene alkylether) was added to these powders. 
Table 1. Specification of AlN powders

\begin{tabular}{|c|c|c|c|c|c|}
\hline Sample No. & $A$ & $B 1, B 2$ & $C$ & $D$ & $E$ \\
\hline \multirow[t]{2}{*}{ Origin } & $\begin{array}{l}\text { Starck } \\
\text { Germany }\end{array}$ & $\begin{array}{l}\text { Powder A } \\
\text { coated with } \\
\text { stearic acid }\end{array}$ & ART USA & - & $\begin{array}{c}\text { Toyo } \\
\text { Aluminium, } \\
\text { Japan }\end{array}$ \\
\hline & Grade C & & A 100 & $\mathrm{~A} 200$ & Grade WF \\
\hline FSSS, $\mu \mathrm{m}$ & $1 \cdot 2$ & as $\mathrm{A}$ & $3-4$ & $3-4$ & 1.94 \\
\hline $\mathrm{BET}, \mathrm{m}^{2} / \mathrm{g}$ & $3 \cdot 7$ & as $\mathrm{A}$ & $2 \cdot 5-4$ & $2 \cdot 5-4$ & $4 \cdot 30$ \\
\hline $\mathrm{Al} \mathrm{wt} \%$ & 64.7 & as $\mathrm{A}$ & 66.05 & $66 \cdot 0$ & - \\
\hline $\mathrm{N} w \mathrm{t} \%$ & $33 \cdot 5$ & as $\mathrm{A}$ & $33 \cdot 0$ & $32 \cdot 7$ & 32.9 \\
\hline $\mathrm{O} w \mathrm{t} \%$ & 1.7 & - & $1 \cdot 0$ & $1 \cdot 1$ & 1.39 \\
\hline Si ppm & - & - & $1000-2000$ & $1000-2000$ & 58 \\
\hline $\begin{array}{l}\text { Water } \\
\text { resistance (h) }\end{array}$ & - & $6-12$ & $2 \cdot 5-4$ & - & $>72$ \\
\hline
\end{tabular}

To measure the $\mathrm{pH}_{\text {iep }}$ at the isoelectric point the powders were dispersed in water (again with Triton deflocculant in case of the powders $C$ and $D$ ), containing $0.01 \mathrm{M} \mathrm{KNO}_{3}$ electrolyte. The suspensions were stabilized at $\mathrm{pH}=2.5$ and titrated with $0.1 \mathrm{M} \mathrm{KOH}$ under vigourous stirring. The $\mathrm{pH}_{\text {iep }}$ was found from the zero crossing of the electroacoustic signal, using a Matec ESA analyser. For three powders XPS measurements were performed using a PHI Model 550 system and $\mathrm{Al} \mathrm{K} \alpha$ radiation. On four powders diffuse reflectance infrared Fourier transform spectroscopy (DRIFT) was used. The region $4000-800 \mathrm{~cm}^{-1}$ was scanned with $4 \mathrm{~cm}^{-1}$ resolution, using 500 scans to improve the signal to noise ratio. Powders were diluted in $\mathrm{KBr}$ and measured against $\mathrm{KBr}$ as reference.

Finally we used thermally stimulated desorption (TPD) to obtain information about adsorbed species and their binding energies to the surface. Similar experiments for the characterization of $\mathrm{Si}_{3} \mathrm{~N}_{4}$ powders have been published earlier. ${ }^{6,7}$ In the TPD equipment the sample is heated under high vacuum, while the desorbed gases are monitored by a mass spectrometer. A loosely pressed powder sample of about $20 \mathrm{mg}$ is placed in a sample holder in the first vacuum chamber, which is pumped by a turbomolecular pump to $10^{-7}$ mbar. After one night, the sample holder is transferred to the main vacuum chamber, which is pumped with an ion getter pump to a vacuum of $<5 \times 10^{-8}$ mbar. In this chamber the sample can be heated by means of an electron gun heater at a rate controlled by a PID controller. Presently the sample is surrounded by stainless steel radiation shields. This limits the maximum sample temperature to about $900^{\circ} \mathrm{C}$, due to outgassing of the radiation shields. The desorbed gases are monitored by means of a quadrupole mass spectrometer (Balzers QMG511). Using the relative ionization cross sec- tions for the different molecules, measured curves were corrected. No attempts were made to calculate ion concentrations.

\section{Experimental Results}

\subsection{XPS measurements}

Results of the XPS measurements on pure and coated AlN powders are summarized in Table 2. The peaks at 77 and $400 \mathrm{eV}$ are ascribed to $\mathrm{Al}$ and $\mathrm{N}$ respectively. The energies correspond to $\mathrm{Al}^{3+}$ and $\mathrm{N}^{3-}$, and thus these peaks are due to bulk AlN. The carbon peaks at $288 \mathrm{eV}$ are due to contamination; probably the same holds for the oxygen peak at $535 \mathrm{eV}$. Powder $\mathrm{C}$ shows silicon peaks at 105 and $180 \mathrm{eV}$. According to the supplier 1000$2000 \mathrm{ppm} \mathrm{Si}$ is present in these powders. Evidently this silicon is present in the surface coating. The carbon peak in this material is shifted over $0.7 \mathrm{eV}$; however, it is uncertain if this indicates the presence of organic carbon atoms. The spectra of powder E contain peaks at 199.2 and $149.2 \mathrm{eV}$

Table 2. XPS peaks for different AIN powders

\begin{tabular}{lcc}
\hline Sample & Peak centre $(\mathrm{eV})$ & Element \\
\hline Starck Grade C & $76 \cdot 7$ & $\mathrm{Al}$ \\
(uncoated) & $400 \cdot 0$ & $\mathrm{~N}$ \\
powder A & 534.7 & $\mathrm{O}$ \\
& 287.8 & $\mathrm{C}$ \\
ART Al00 & 76.9 & $\mathrm{Al}$ \\
powder C & $400 \cdot 0$ & $\mathrm{~N}$ \\
& 534.7 & $\mathrm{O}$ \\
& $287 \cdot 1$ & $\mathrm{C}$ \\
& $105 \cdot 0 ; 180 \cdot 0$ & $\mathrm{Si}$ \\
Toyalnite & 77.4 & $\mathrm{Al}$ \\
powder E & $119 \cdot 02 ; 149 \cdot 2$ & $\mathrm{P}$ (from phosphate) \\
& $400 \cdot 3$ & $\mathrm{~N}$ \\
& $535 \cdot 6$ & $\mathrm{O}$ \\
& 287.8 & $\mathrm{C}$ \\
\hline
\end{tabular}


which are assigned to $\mathrm{P}$ in phosphate groups. The shift of the oxygen peak with $0.9 \mathrm{eV}$ may also be due to the bonding in the phosphate group. The presence of phosphate is in accordance with a remark in Ref. 8.

\subsection{DRIFT spectra}

All powders show about 8 strong bands between 600 and $1400 \mathrm{~cm}^{-1}$ which can be assigned to lattice phonons of AlN. ${ }^{9}$ A weak band at $1973 \mathrm{~cm}^{-1}$ in powder $\mathrm{E}$ agrees well with the $3 \mathrm{TO}_{1}$ mode found in Ref. 9. Broad IR bands at $1600 \mathrm{~cm}^{-1}$ and around $3400 \mathrm{~cm}^{-1}$ are due to weakly bonded water molecules. Powders B clearly show the $\mathrm{CH}_{2}$ stretching bands around $2800 \mathrm{~cm}^{-1}$, originating from the stearic acid coating. The spectra of the powders $C$ and $D$ show two extra peaks which could not be assigned unambiguously. For instance a peak at $2160 \mathrm{~cm}^{-1}$, present in both $C$ and $D$ may be assigned to a metal-hydrogen band. Ref. 10 attributes this band on pure AlN to $\mathrm{Al}-\mathrm{H}$ stretching, although the authors note that the frequency is rather high in comparison with $\mathrm{AlH}$ in aluminium hydrides. However, the same frequency is observed for $\mathrm{Si}-\mathrm{H}$ on $\mathrm{Si}_{3} \mathrm{~N}_{4}$ powders. ${ }^{11}$ The band is not present in the uncoated powder, and since XPS shows the presence of $\mathrm{Si}$ on the surface of powder $\mathrm{C}$ this suggests that it is due to an $\mathrm{SiH}$ vibration. However, the absorption is also present in powder E, where no Si was found with XPS. A broad band in both powders at $3200 \mathrm{~cm}^{-1}$ may be due to $\mathrm{NH},{ }^{9}$ while a sharper peak at $2965 \mathrm{~cm}^{-1}$ may indicate the presence of carbon. These assignments remain uncertain, however.

\subsection{Temperature programmed desorption}

TPD spectra of the different powders are shown in Figs 1-5. All powders show a high desorption peak of water at about $100^{\circ} \mathrm{C}$. This is clearly physisorbed water. However, the water desorption continues up to about $600^{\circ} \mathrm{C}$. By analogy with the reaction of silanol groups on silicon nitride, this may be due to the surface reaction

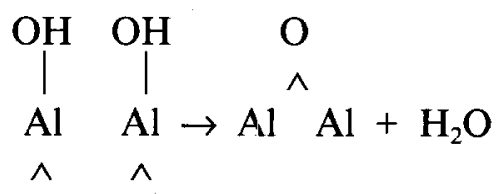

After coating with stearic acid (powders B) the physisorbed water peak has a much lower intensity. As could be expected, the stearic acid coated material shows many peaks due to decomposition products of the organic coating, e.g. $\mathrm{C}_{6} \mathrm{H}_{11}, \mathrm{C}_{6} \mathrm{H}_{7}$, $\mathrm{C}_{6} \mathrm{H}_{5}, \mathrm{C}_{4} \mathrm{H}_{9}, \mathrm{C}_{4} \mathrm{H}_{7}, \mathrm{C}_{3} \mathrm{H}_{7}, \mathrm{C}_{3} \mathrm{H}_{5}, \mathrm{C}_{2} \mathrm{H}_{5}$, and lower masses. Figure 2 shows two of these peaks, at mass 41 and 55 respectively. The hydrocarbons show a desorption maximum at about $400^{\circ} \mathrm{C}$,

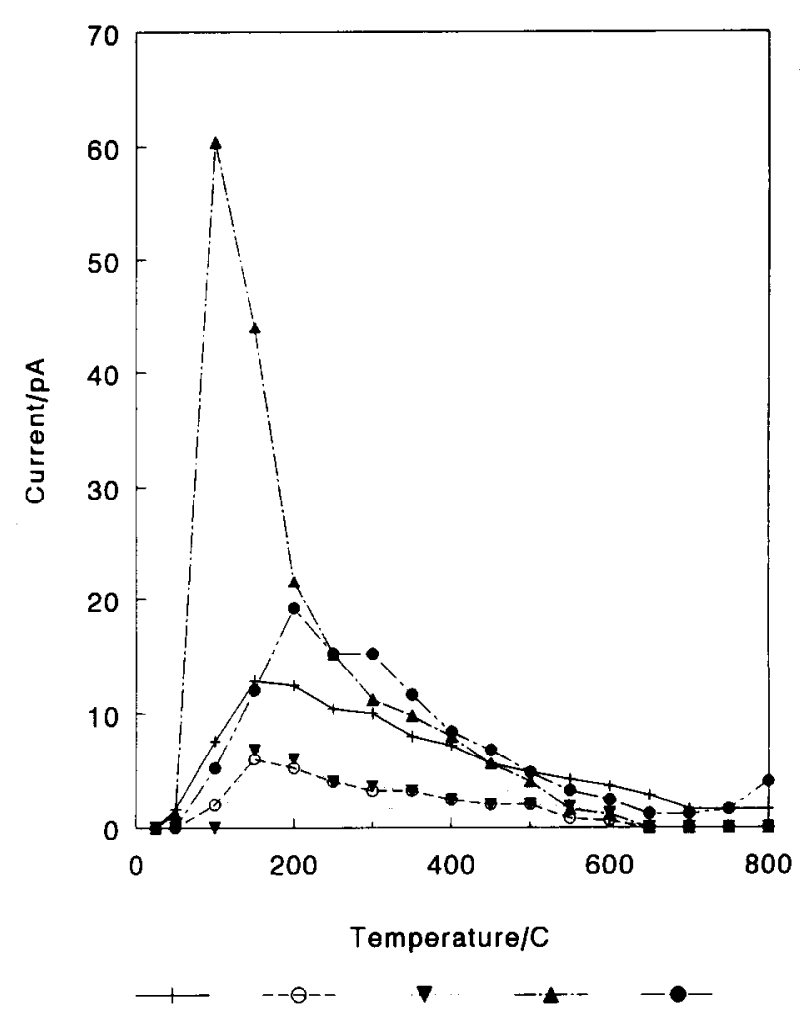

Fig. 1. TPD mass spectrum of uncoated $\mathrm{AlN}$ (powder A). Legends from left to right $+\mathrm{M}=2, \mathrm{H}_{2} ; \mathrm{OM}=16$ and $\nabla \mathrm{M}$ $=17$ overlapping peaks $\mathrm{NH}_{2}, \mathrm{NH}_{3} ; \mathbf{\Delta} \mathbf{M}=18, \mathrm{H}_{2} \mathrm{O}$; $\mathrm{M}=28, \mathrm{~N}_{2}$.

indicating that the coating is chemically bonded to the AlN surface. No difference was observed between the powders coated from stearic-acid benzene or stearic-acid cyclohexane solutions.

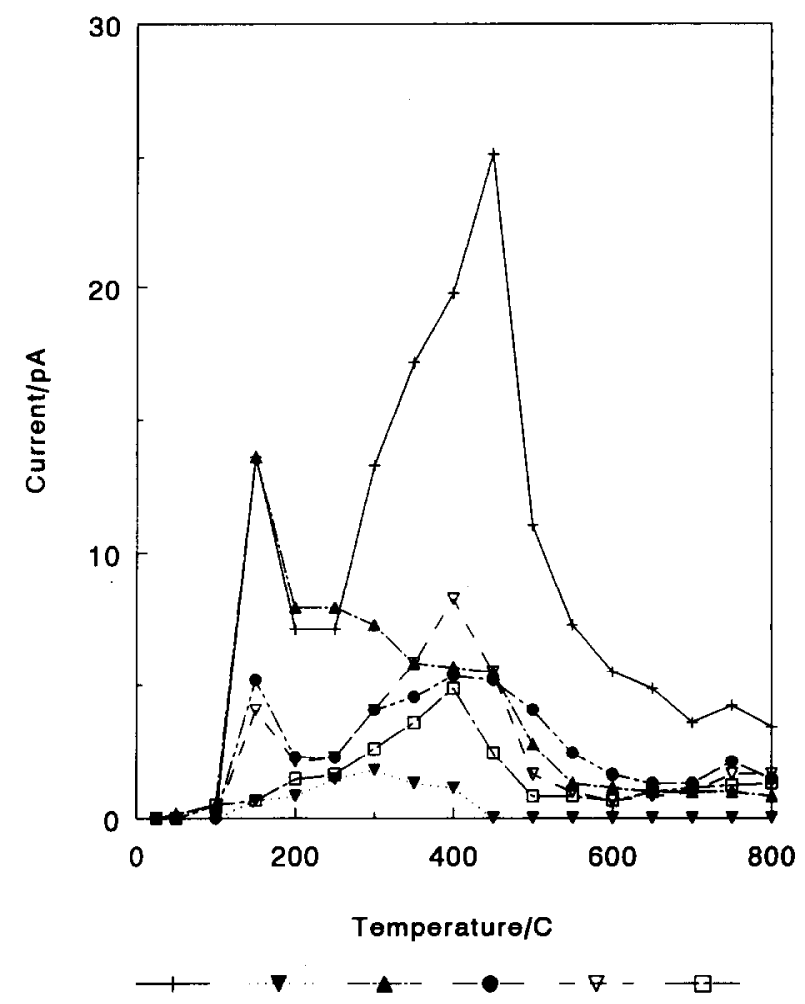

Fig. 2. TPD mass spectrum of stearic acid coated AlN (pow$\operatorname{der} B$ ). Legends from left to right $+\mathrm{M}=2, \mathrm{H}_{2} ; \nabla \mathbf{M}=17$, $\mathrm{NH}_{3} ; \Delta \mathrm{M}=18, \mathrm{H}_{2} \mathrm{O} ; \mathrm{M}=28, \mathrm{~N}_{2} ; \nabla \mathrm{M}=41, \mathrm{C}_{3} \mathrm{H}_{5} ; \square$ $\mathrm{M}=55, \mathrm{C}_{4} \mathrm{H}_{7}$. 


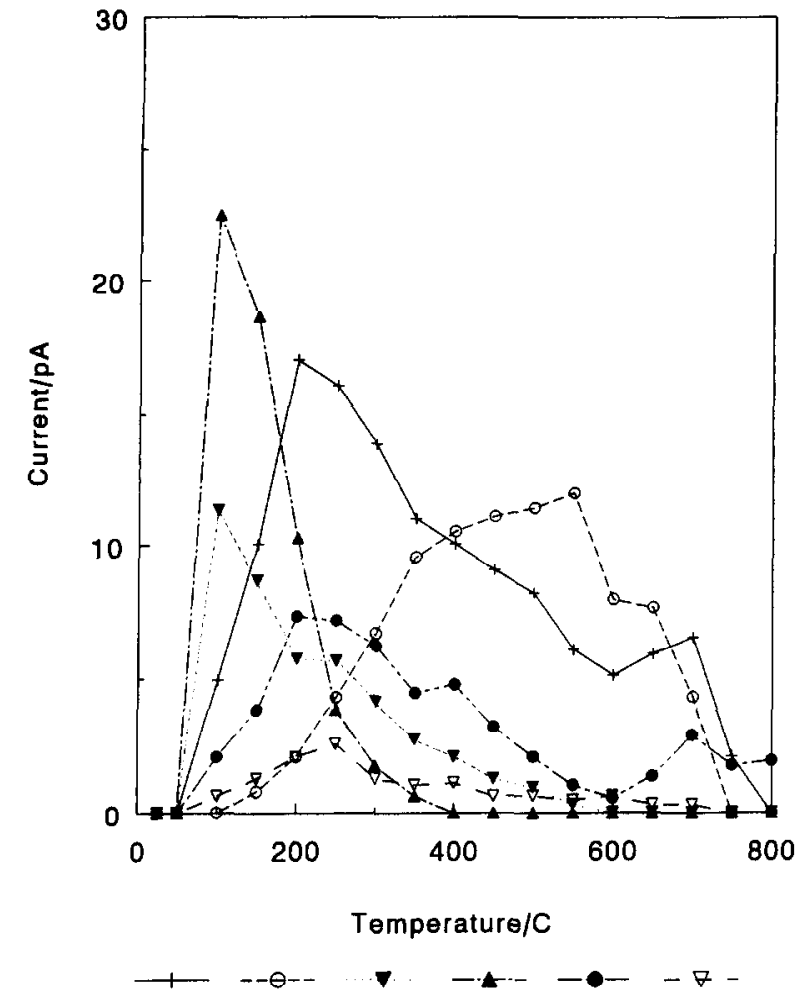

Fig. 3 TPD mass spectrum of water resistant AlN (powder C). Legends from left to right $+\mathrm{M}=2, \mathrm{H}_{2} ; \bigcirc \mathrm{M}=16, \mathrm{NH}_{2}$; $\nabla \mathrm{M}=17, \mathrm{OH} ; \boldsymbol{\Delta} \mathrm{M}=18, \mathrm{H}_{2} \mathrm{O} ; \boldsymbol{M}=28, \mathrm{~N}_{2} ; \nabla \mathrm{M}=41$, $\mathrm{C}_{3} \mathrm{H}_{5}$.

Powder $\mathrm{C}$ shows a peak at mass 41 , which may be due to hydrocarbon (note that in blank runs hydrocarbons have never been found, due to the

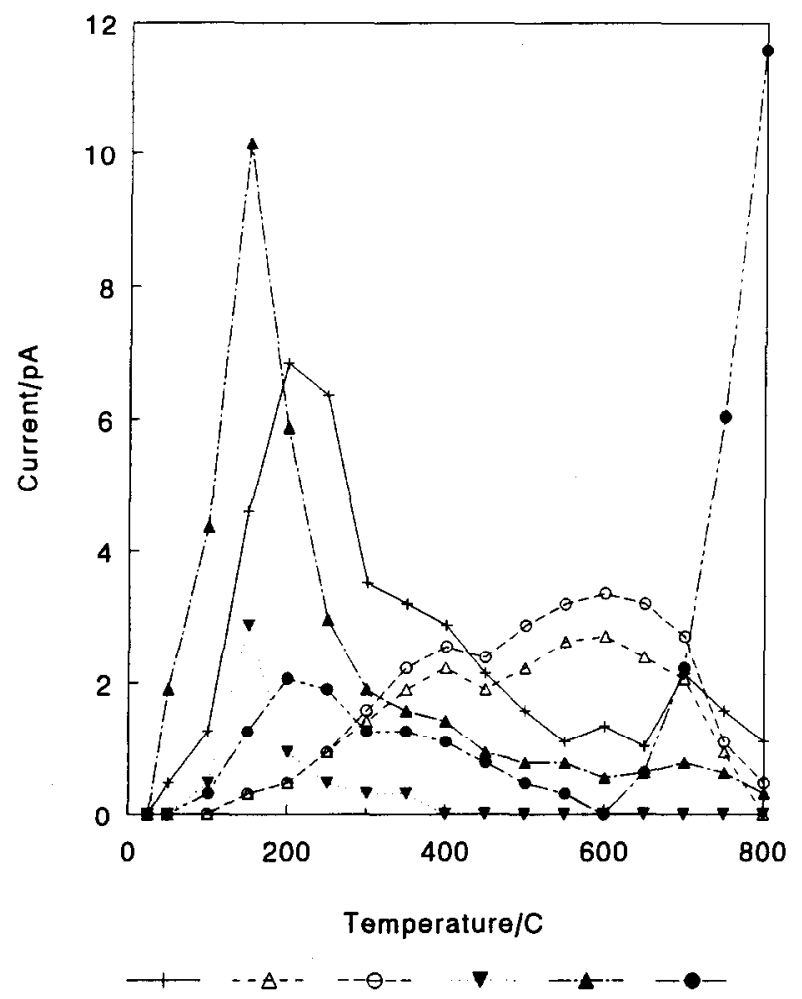

Fig. 4. TPD mass spectrum of water resistant AlN (powder D). Legends from left to right $+M=2, H_{2} ; \Delta M=15, N H$; $\mathrm{O}=16, \mathrm{NH}_{2} ; \boldsymbol{\nabla}=17, \mathrm{OH} ; \boldsymbol{\Delta} \mathrm{M}=18, \mathrm{H}_{2} \mathrm{O}$ $\mathrm{M}=28, \mathrm{~N}_{2}$

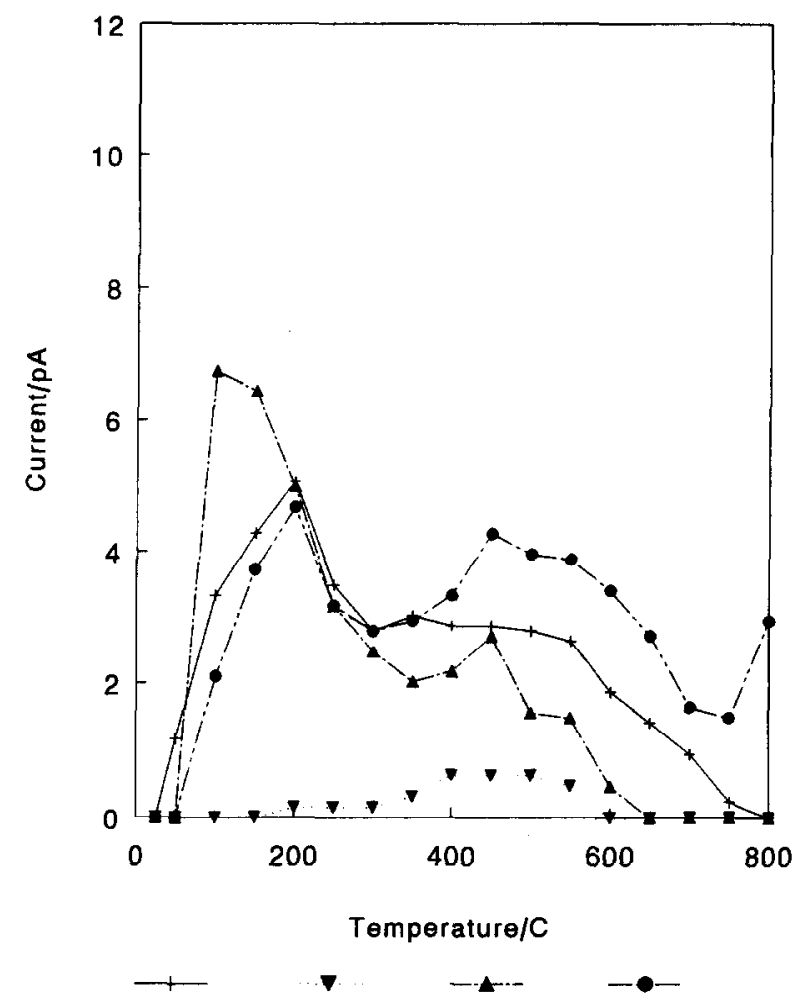

Fig. 5. TPD mass spectrum of water resistant AIN (powder E). Legends from left to right $+\mathrm{M}=2, \mathrm{H}_{2} ; \nabla \mathrm{M}=16$ and 17 overlapping peaks $\mathrm{NH}_{2}, \mathrm{NH}_{3} ; \mathbf{M}=18, \mathrm{H}_{2} \mathrm{O} ; \mathrm{M}=28, \mathrm{~N}_{2}$.

clean vacuum system). The TPD spectrum of D shows a strong peak at mass 28 above $700^{\circ} \mathrm{C}$, which is not observed in the other powders. This may be due to $\mathrm{Si}$ instead of $\mathrm{N}_{2}$, as shown by the XPS and suggested by the DRIFT spectra, however, the fact that it is not observed with powder $\mathrm{C}$ contradicts this. Powders A, C, D and E all show desorption of $\mathrm{NH}_{3}$ at about $150^{\circ} \mathrm{C}$, indicating a wcak bonding. As mentioned above, AlN reacts with water to form $\mathrm{AlOOH}$ and $\mathrm{NH}_{3}$. Part of the ammonia formed by reaction of AlN with water vapour will remain adsorbed at the surface and may cause the low temperature desorption peak.

In all powders we find desorption of $\mathrm{H}_{2}$ and $\mathrm{N}_{2}$. The peaks are closely correlated and show maxima at 200 and about $400^{\circ} \mathrm{C}$. A similar behaviour was found in $\mathrm{Si}_{3} \mathrm{~N}_{4}$ powders. ${ }^{7}$ In silicon nitride there is ample evidence for the presence of $\mathrm{OH}$ and NH surface groups. ${ }^{13,14}$ Therefore we assume that the desorption of hydrogen and nitrogen from the AlN powders is also due to the presence of $\mathrm{NH}$ groups at surface sites. Powders C, D and to a lesser extent $\mathrm{E}$ all show a peak at about $500-600^{\circ} \mathrm{C}$ for mass 15 and 16 . These peaks are also closely correlated and are therefore attributed to $\mathrm{NH}$ and $\mathrm{NH}_{2}$. Desorption of powder $\mathrm{E}$ is low over the whole temperature range. No hydrocarbon peaks were detected for this powder. In view of the XPS results this may indicate a coating with phosphate without organic groups. 
Milling of the uncoated AlN powder for $70 \mathrm{~h}$ in dry propanol gives a TPD spectrum identical with that of the untreated powder, i.e. the adsorbed species are not removed by this treatment. It also shows that AlN is quite stable in propanol, in agreement with the observation in Ref. 1.

We have also measured the TPD spectrum of uncoated Starck powder after heat treatment at $1000^{\circ} \mathrm{C}$ in nitrogen. Most of the $\mathrm{H}_{2}, \mathrm{~N}_{2}$, and $\mathrm{H}_{2} \mathrm{O}$ are removed, while the $\mathrm{NH}_{3}$ and $\mathrm{NH}_{2}$ peaks disappear almost completely. ${ }^{12}$ A similar observation was made for silicon nitride powders. ${ }^{\text {? }}$

\subsection{Electroacoustic measurements}

The stability of the powders was measured by following the $\mathrm{pH}$ of aqueous suspensions at room temperature. Figure 6 shows the change in $\mathrm{pH}$ for $0.5 \mathrm{wt} \%$ suspensions of five different powders. The uncoated powder A starts to react from the very beginning. The end value for these dilute suspensions is about $\mathrm{pH} 11$. As shown earlier the addition of Triton surfactant does not influence these results. ${ }^{5}$ The figure shows that both the stearic acid coated powder $B$ and powder $E$ are stable for long times at room temperature. This confirms earlier results of Egashira et al. ${ }^{3}$ No difference was observed between B1 and B2. Powders C and D are stable up to about $30 \mathrm{~h}$, as specified by the supplier. One may suspect that the stability depends on the starting $\mathrm{pH}$ of the dispersions. Therefore we repeated the experiment with powder $\mathrm{E}$, the most stable powder, using different ini-

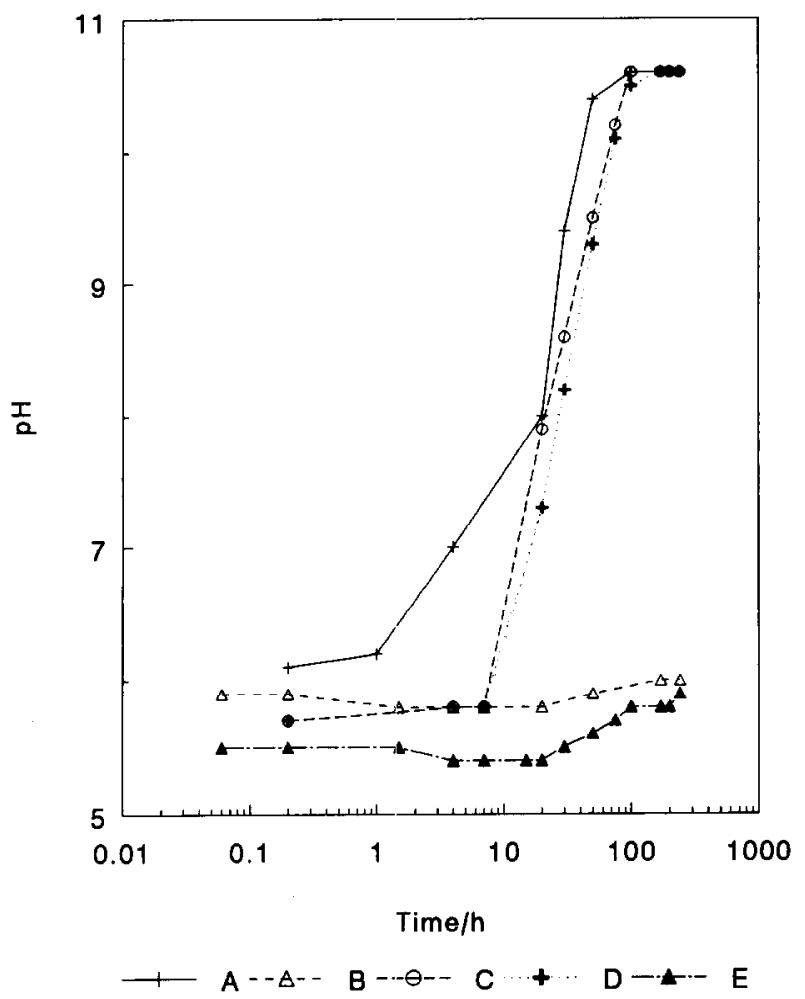

Fig. 6. Time dependence of $\mathrm{pH}$ of $0.05 \mathrm{wt} \%$ dispersions of AlN (powders $\mathrm{A}-\mathrm{E}$ ) in water.

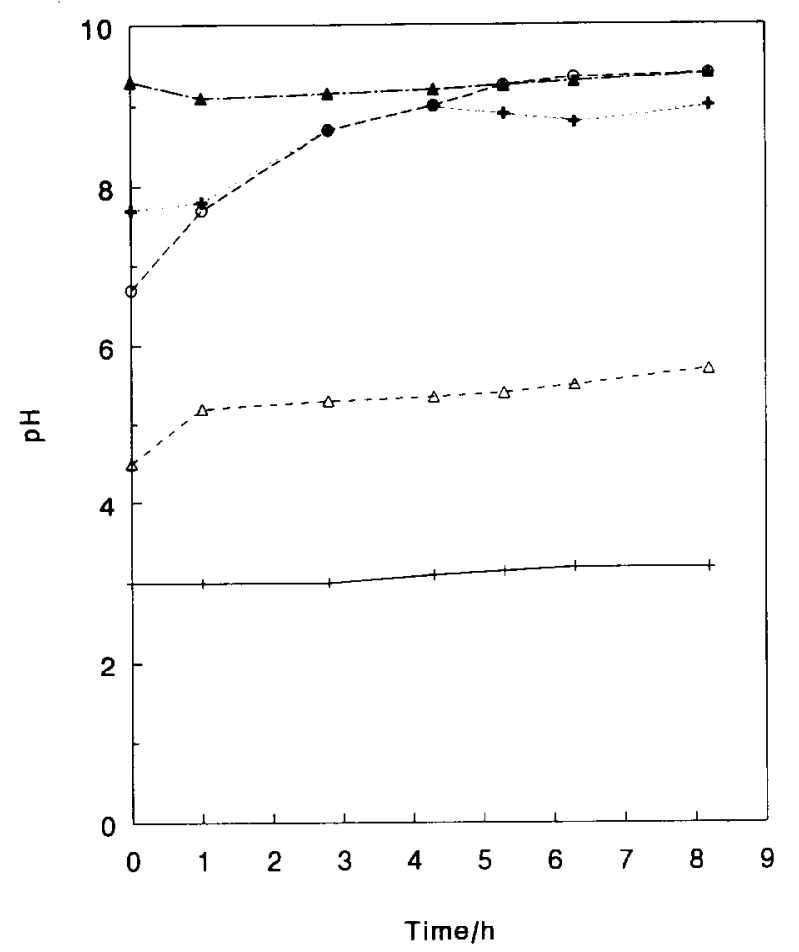

Fig. 7. Stability of powder $\mathrm{E}$ in water with different starting $\mathrm{pH}$.

tial $\mathrm{pH}$ values. Figure 7 shows the results. Suspensions of powder $\mathrm{E}$ show a decrease in stability at high $\mathrm{pH}$ values. For slip casting one uses much higher solid loadings. Therefore we followed the $\mathrm{pH}$ of $30 \mathrm{vol} \%$ ( $58 \mathrm{wt} \%$ ) suspensions as a function of time (Fig. 8). The decomposition rate is considerably enhanced and hydrolysis of the uncoated

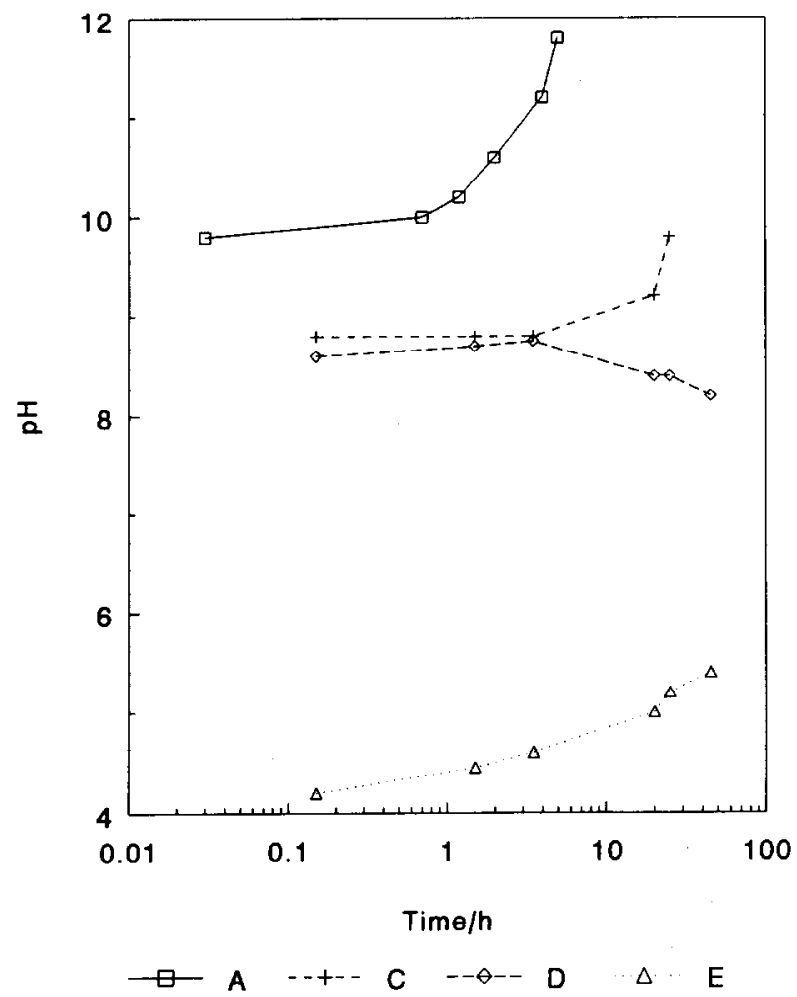

Fig. 8. Time dependence of $\mathrm{pH}$ of $30 \mathrm{vol} \%$ slips of AIN powders in water. 
Table 3. Isoelectric point for suspensions with different solid contents

\begin{tabular}{lcc}
\hline Sample & Conc. $w t^{\%}$ & $p H_{\text {iep }}$ \\
\hline Starck Grade C & 4 & $9 \cdot 7$ \\
(powder A) & 10 & $8 \cdot 9$ \\
& 25 & $8 \cdot 8$ \\
& 50 & $8 \cdot 8$ \\
ART A100 & 4 & $8 \cdot 5$ \\
(powder C) & 10 & $8 \cdot 5$ \\
& 25 & $8 \cdot 4$ \\
ART A200 & 50 & $8 \cdot 1$ \\
(powder D) & 4 & $7 \cdot 9$ \\
& 10 & $7 \cdot 8$ \\
& 25 & $7 \cdot 7$ \\
Toyalnite & 50 & $7 \cdot 5$ \\
(powder E) & 4 & $6 \cdot 0$ \\
& 10 & $6 \cdot 0$ \\
& 25 & $6 \cdot 0$ \\
\hline
\end{tabular}

powder is visible within $1 \mathrm{~h}$. For powder B the reaction starts between 24 and $48 \mathrm{~h}$. Due to the exothermal nature of the reaction the rate rapidly increases and the slip even became a solid mass. Note that although suspensions are made with water of $\mathrm{pH}=7$, the $\mathrm{pH}$ at the first measuring point after $2 \mathrm{~min}$ has changed considerably. Suspensions of powder $\mathrm{E}$ become acidic, powders $\mathrm{C}$ and D slightly basic. Results of the determination of the isoelectric point by means of ESA measurements are shown in Table 3. Measurements were performed for four different concentrations of the suspensions, viz. 4, 10, 25 and $50 \mathrm{wt} \% \mathrm{AlN}$ in water. There is a slight tendency towards decreasing $\mathrm{pH}_{\text {iep }}$ values for increasing concentrations. The surface charge is positive below the isoelectric point and negative above. $\mathrm{The}^{\mathrm{pH}}$ iep value of 8.9 for the uncoated powder is in close agreement with the value of 9.0 found by Seitz et al. ${ }^{15}$ From a comparison with alumina these authors concluded that $\mathrm{Al}_{2} \mathrm{O}_{3}$ and $\mathrm{AIN}$ exhibit a similar surface. This would mean that the surface contains amphoteric $\mathrm{AlOH}$ groups, which may be ionized in solution according to the following reactions:

$$
\begin{gathered}
\mathrm{AlOH}_{2}{ }^{+} \rightleftharpoons \mathrm{AlOH}+\mathrm{H}^{+}(\mathrm{aq}) \\
\mathrm{K}_{1}=\left(\mathrm{H}^{+}\right)(\mathrm{AlOH}) /\left(\mathrm{AlOH}_{2}^{+}\right) \\
\mathrm{AlOH} \rightleftharpoons \mathrm{AlO}^{-}+\mathrm{H}^{+}(\mathrm{aq}) \\
\mathrm{K}_{2}=\left(\mathrm{H}^{+}\right)\left(\mathrm{AlO}^{-}\right) /(\mathrm{AlOH})
\end{gathered}
$$

The point of zero charge (pzc) is found when $\left(\mathrm{AlOH}_{2}^{+}\right)=\left(\mathrm{AlO}^{-}\right)$. From eqns 4 and 5 it follows that this is the case when $\mathrm{pH}_{\mathrm{pzc}}=\left(\mathrm{pK}_{1}+\mathrm{pK}_{2}\right) / 2$. Assuming $\mathrm{pH}_{\text {iep }}=\mathrm{pH}_{\mathrm{pzc}}$ we find $\mathrm{pK}_{1}+\mathrm{pK}_{2}=$ 17.8. One also finds the ratio of basic to acid sites as a function of $\mathrm{pH}$ :

$\log \left(\mathrm{AlOH}_{2}^{+}\right) /\left(\mathrm{AlO}^{-}\right)=\mathrm{pK}_{1}+\mathrm{pK}_{2}-2 \mathrm{pH}=17 \cdot 8-2 \mathrm{pH}(6)$

Powder $\mathrm{E}$ has a $\mathrm{pH}_{\text {iep }}$ of $6 \cdot 0$, which indicates the presence of acidic surface groups. This is in accordance with the observation of phosphate groups in the XPS and IR spectra. The behaviour of powder $\mathrm{D}$ indicates that the organosilicon coating results in a $\mathrm{pH}_{\text {iep }}$ of about 7.5. The $\mathrm{pH}_{\text {iep }}$ of pow$\operatorname{der} \mathrm{C}$ is in between the value of uncoated powder $A$ and powder $\mathrm{D}$, suggesting that the surface is incompletely covered. The higher water sensitivity of $\mathrm{C}$ compared to $\mathrm{D}$ points in the same direction. Both powders were poorly dispersable in water which is related to the hydrophobic coating.

\section{Summary and Conclusions}

The surface of coated and uncoated AlN powder has been investigated by means of XPS, DRIFT spectroscopy, TPD and electrokinetic measurements. Uncoated AlN has a surface similar to alumina with amphoteric $\mathrm{AlOH}$ groups. The stability of AlN in water increases in the sequence pure AlN $<$ ART coated $<$ stearic acid coated $<$ Toyalnite coated. The surface of ART powder $C$ seems to be only partially covered by a coating containing both silicon and organic carbon. Stearic acid gives a better protection, but a considerable quantity of this organic compound is present on the surface, which has to be removed before sintering. The Toyalnite powder contains phosphate groups. Due to the coatings the isoelectric point shifts from $\mathrm{pH}$ 9 for pure AlN via 7.5 for ART powder to 5.8 for the Toyalnite powder.

\section{Acknowledgements}

T. Verhoeven is acknowledged for the XPS measurements and interpretation, $J$. Vaessen and G. Koekebier for help with ESA measurements and C. Verhagen for advice on the DRIFT spectra.

\section{References}

1. Bowen, P., Highfield, J. G., Mocellin, A. \& Ring, T. A., Degradation of aluminium nitride powder in aqueous environment. J. Am. Ceram. Soc, 73 (1990) 724-8.

2. Reetz, T., Mönch, B. \& Saupe, M., Aluminium hydrolysis. cfi/Ber. DKG, 69 (1992) 464-5.

3. Egashira, M., Shimizu, Y. \& Takatsuki, S., Chemical surface treatments of aluminium nitride powder suppressing its reactivity with water. J. Mater. Sci. Letters, 10 (1991) 994-6.

4. Egashira, M., Shimizu, Y., Takao, Y., Yamaguchi, R. \& Ishikawa, Y., Effect of carboxylic acid adsorption on the hydrolysis and sintered properties of aluminium nitride powder. J. Am. Ceram. Soc., 77 (1994) 1793-8.

5. Gorter, H., Gerretsen, J. \& Terpstra, R. A., 3rd Euro Ceramics. Vol. 1, eds P. Duran \& J. F. Fernandez. Faenze Editrice Iberica, 1993, pp. 615-20.

6. Kawamoto, M., Ishizaki, K \& Ishizaki, C., Characterization 
of silicon nitride powders by a temperature programmed desorption study. In Euro-Ceramics, Vol. 2, eds G. de With, R. A. Terpstra \& R. Metselaar. Elsevier Appl. Sci., London, 1988 , p. $2 \cdot 120$.

7. Chen, M., Van Rutten, J. W. T. \& Metselaar, R., Study of temperature programmed desorption of silicon nitride and sialon by means of mass spectrometry. In 3 rd EuroCeramics, Vol. 1, eds P. Duran \& J. F. Fernandez. Faenza Editrice Iberica, 1993, p. 597-602.

8. Sheppard, L. M., Recent developments and the outlook for electronic ceramics: Surge in electronic materials continues - Part 1. Silicates Industr., 1993, pp. 839.

9. Collins, A. T., Lightowlers, E. C. \& Dean, P. J., Lattice vibration spectra of aluminum nitride. Phys. Rev., 158 (1967) 833-8.

10. Merle-Méjean, T., Baraton. M-I., Quintard, P., Laurent, Y. \& Lorenzelli, V., Fourier-transform infrared characterization of an aluminium nitride surface. J. Chem. Soc. Faraday Trans., 89 (1993) 3111-5.

11. Busca, G., Lorenzelli, V., Porcile, G., Baraton, M. I.,
Quintard, P. \& Marchand, R., FT-IR study of the surface properties of silicon nitride. Mater. Chem. Phys., 14 (1986) 123-40.

12. Chen, M. \& Metselaar, R., Study of temperature programmed desorption of aluminium nitride powders by means of mass spectrometry. In Charting the Future, Proc. 8th CIMTEC Conference, ed. P. Vincenzini. Techna Faenza, 1995, pp. 2125-36.

13. Bergström, L. \& Bostedt, E., Surface chemistry of silicon nitride powders: Electrokinetic behaviour and ESCA studies. Coll. and Surfaces, 49 (1990) 183-197.

14. Hackley, V. A. \& Malghan, S. G., The surface chemistry of silicon nitride powder in the presence of dissolved ions. J. Mater. Sci., 29 (1994) 420-30.

15. Seitz, K., Hessel, F., Güther, H.-M., Roosen, A. \& Aldinger, F., Comparison of the surface characteristics of alumina and aluminium nitride. In Ceramic Trans. 22 Ceramic Powder Sci. IV, eds S. Hirano, G. L. Messing \& H. Hausner. Am. Ceram. Soc., Westerville, 1991 , pp. $227-34$. 